\title{
A Prevenção e Controlo de Infeção: Um Esforço Conjunto
}

\section{Infection Prevention and Control: A Joint Effort}

Nuno Rocha Pereira ${ }^{1}$, Paulo Aguiar Andrade ${ }^{1}$

PALAVRAS-CHAVE: Infeção Hospitalar/prevenção e controlo; SARS-CoV-2

KEYWORDS: COVID-19; Cross Infection/prevention \& control; SARS-CoV-2

Estima-se que em 2050, no mundo inteiro, possam existir cerca de 10 milhões de mortes associadas à resistência aos antimicrobianos, superando as mortes atribuíveis a doença neoplásica. ${ }^{1}$ Em 2015, em Portugal, estimaram-se 24021 casos de infeção por bactérias multirresistentes, responsáveis por 1158 mortes, das quais 63,5\% associadas aos cuidados de saúde. ${ }^{2}$

Assim, as infeções nosocomiais, a resistência aos antimicrobianos e as doenças infeciosas emergentes são fatores determinantes na qualidade e segurança dos cuidados de saúde, condicionando uma significativa morbimortalidade que impede o seu normal funcionamento.

O estabelecimento e desenvolvimento de estruturas dedicadas ao controlo de infeção tem um efeito direto na diminuição das infeções nosocomiais, com eviden- te benefício para o doente. ${ }^{3}$ Em Portugal, foi criado o Programa de Prevenção e Controlo de Infeções e de Resistência aos Antimicrobianos (PPCIRA), de âmbito nacional e apresentando como objetivos gerais a redução da taxa de infeção associada aos cuidados de saúde, a promoção do uso correto de antimicrobianos e a diminuição da taxa de micro-organismos com resistência a antimicrobianos, assentando na formação e educação a profissionais, vigilância epidemiológica e normalização de estruturas, procedimentos e práticas clínicas. ${ }^{4}$

A pandemia por SARS-CoV-2 evidenciou a importância da prevenção e controlo de infeção entre os profissionais. É fundamental que este interesse se materialize na implementação e perenidade de práticas e procedimentos corretos e rigorosos, garantindo um salto qualitativo nos cuidados prestados. 
Assim, a Comissão Técnica Transversal (CTT) do PPCIRA tem por missão a uniformização e orientação de atuação em todo o grupo CUF, munindo-se da melhor evidência científica disponível, em articulação com os Grupos Coordenadores Locais (GCL), dotados de recursos necessários para a prossecução dos seus objetivos.

Cabe aos profissionais do grupo, como um todo, contribuir com espírito crítico nesta desejada melhoria contínua da qualidade e segurança, que resultará numa elevação dos cuidados prestados, garantindo a satisfação dos doentes e a realização dos profissionais.

\section{RESPONSABILIDADES ÉTICAS}

CONFLITOS DE INTERESSE: Os autores declaram não possuir conflitos de interesse.

SUPORTE FINANCEIRO: O presente trabalho não foi suportado por nenhum subsídio ou bolsa.

PROVENIÊNCIA E REVISÃO POR PARES: Não comissionado; revisão externa por pares.

\section{ETHICAL DISCLOSURES}

CONFLICTS OF INTEREST: The authors have no conflicts of interest to declare.

FINANCING SUPPORT: This work has not received any contribution, grant or scholarship.

PROVENANCE AND PEER REVIEW: Not commissioned; externally peer reviewed.

\section{REFERÊNCIAS}

1. O'Neill J. Tackling Drug-Resistant Infections Globally: Final Report and Recomendations. 2016. [accessed May 2020] Available from: https://amr-review.org/sites/default/files/160518_Final\%20paper_with\%20cover.pdf.

2. Cassini A, Högberg LD, Plachouras D, Quattrocchi A, Hoxha A, Simonsen GS, et al. Attributable deaths and disability-adjusted life-years caused by infections with antibiotic-resistant bacteria in the EU and the European Economic Area in 2015: a population-level modelling analysis. Lancet Infect Dis 2019;19:56-66. doi: 10.1016/S1473-3099(18)30605-4.

3. Haley RW, Culver DH, White JW, Morgan WM, Emori TG, Munn VP, et al. The efficacy of infection surveillance and control programs in preventing nosocomial infections in US hospitals. Am J Epidem. 1985;121:182-205.

4. Despacho 15423/2013. Diário da República 2a série n²29, 26 de novembro de 2013. 